\title{
Measurement of Cellular Network's Availability and Reliability based on the Signaling Ladder Diagram
}

\author{
Sigit Haryadi
}

Institut Teknologi Bandung

February 2018

Paper DO/10.17605/OSF.1O/HWVM8

Citation: Haryadi, S. (2018, February 26). Measurement of Cellular Network's Availability and Reliability based on the Signaling Ladder Diagram. Retrieved from osf.io/preprints/inarxiv/hwvms

\section{Abstract}

Here is described the measurement principle of network performance and service quality with reference to the Signaling Ladder Diagram (SLD), particularly is limited to the application of cellular networks to measure availability and accessibility.

\section{Abstract Equation of Key Performance Indicator of Availability and Accessibility of the Cellular Network}

Availability and accessibility of radio network will directly perceive by the customer, therefore, I recommend using these two parameters as an option to fit into the network parameters of KPI (Key Performance Indicator).

\subsection{Abstract Equation of Radio Network Unavailability}

Unavailability is showing conditions in a location that does not exist a network or the network is experiencing a failure, then the measured network is considered as no network.

Abstract Equation of Radio network unavailability

RadioNetworkUnAvailability $=\frac{\text { probing attempts with mobile services not available }}{\text { all probingattempts }}$

\subsection{Abstract Equation of Network Non-Accessibility}

Non-accessibility is a condition in which the customer cannot make registration, which marked the provider logo not appearing on the UE (User Equipment). Note that, if the network is not available, it certainly also means that no accessibility. As a result of non-accessibility is the 
subscribers do not have an access to the provider. Sometime non-accessibility occur due to the condition that the customer does not pass the authentication.

Abstract Equation of Network Non-accessibility:

NetworkNonAccessibility $=\frac{\text { unsuccessf ul registrations on the providernetworks }}{\text { all registration attemp }}$

\section{Types of Network non-accessibility to attach the services.}

Accessed value is measured when the customers have started to reach the service, such as going to call or want to use the internet connection.

a. Accessibility for attaching to the phone service, measured by the success of UE (user equipment) perform attach, and marked by the UE receives attach accept the message, otherwise, if not received, then there is a condition known as an attach-failure.

b. Accessibility for attaching to the internet service, measured by the success of UE performs a PDP context. After the UE sends the first "Activate PDP Context Request" message, then it should receive the "Activate PDP context accept" message, otherwise, if not received, then there is a condition known as s PDP Context Activation Failure.

\section{Signaling Ladder Diagram}

Table 1. Signaling Ladder Diagram of PDP Context Activation on of Cellular Network refer to ETSI Standard

\begin{tabular}{|l|l|l|l|}
\hline \multicolumn{1}{|c|}{ TRIGGER POINT } & \multicolumn{1}{|c|}{ SIGNAL NAME } & \multicolumn{1}{|c|}{$\begin{array}{l}\text { OUTGOING } \\
\text { NETWORK } \\
\text { ELEMENT }\end{array}$} & \multicolumn{1}{|c|}{$\begin{array}{r}\text { INCOMING } \\
\text { NETWORK } \\
\text { ELEMENT }\end{array}$} \\
\hline $\begin{array}{l}\text { START: Mobile Station } \\
\text { (MS) sends the "Activate } \\
\text { PDP context } \\
\text { Request" message (Layer } \\
\text { 3). }\end{array}$ & Activate PDP Context & MS & SGSN \\
\hline & $\begin{array}{l}\text { Create PDP Context } \\
\text { Request }\end{array}$ & SGSN & GGSN \\
\hline & $\begin{array}{l}\text { Create PDP Context } \\
\text { Response }\end{array}$ & GGSN & SGSN \\
\hline & $\begin{array}{l}\text { Radio Access Bearer } \\
\text { Assignment Request }\end{array}$ & SGSN & RAN \\
\hline & Radio Bearer Setup & RAN & MS \\
\hline & $\begin{array}{l}\text { Radio Bearer Setup } \\
\text { Complete }\end{array}$ & MS & RAN \\
\hline & & & \\
\hline
\end{tabular}




\begin{tabular}{|l|l|l|l|}
\hline & $\begin{array}{l}\text { Radio Access Bearer } \\
\text { Assignment Response }\end{array}$ & RAN & SGSN \\
\hline & $\begin{array}{l}\text { Update PDP Context } \\
\text { Request } \\
\text { Update PDP Context } \\
\text { Response }\end{array}$ & SGSN & GGSN \\
\hline $\begin{array}{l}\text { STOP: MS receives the } \\
\text { "Activate PDP context } \\
\text { Accept" message (Layer 3) }\end{array}$ & $\begin{array}{l}\text { Activate PDP Context } \\
\text { Accept }\end{array}$ & SGSN & SGSN \\
\hline
\end{tabular}

Explanation

1. START: Mobile Station (MS) sends the "Activate PDP context " message to SGSN

2. SGSN successfully received "Activate PDP context " from MS, will send "Create PDP Context Request" to GGSN

3. GGSN successfully received "Create PDP Context Request" from SGSN will send "Create PDP Context Response" to SGSN

4. SGSN successfully received "Create PDP Context Response" from GGSN will send "Radio Access Bearer Assignment Request" to RAN

5. RAN successfully received "Radio Access Bearer Assignment Request" will send "Radio Bearer Setup" to MS

6. MS successfully received "Radio Bearer Setup", will send "Radio Bearer Setup Complete" to RAN

7. RAN successfully received "Radio Bearer Setup Complete" will send "Radio Access Bearer Assignment Response" to SGSN

8. SGSN successfully received "Radio Access Bearer Assignment Response" will send "Update PDP Context Request" to GGSN

9. GGSN successfully received "Update PDP Context Request" will send "Update PDP Context Response" to SGSN"; and

10. STOP (Success): MS receives the "Activate PDP context Accept" message from SGSN

\section{Analysis}

The measurement data of PDP Context activation are based on the counter in the SGSN / GGSN which records all incoming signals, whether successful or failed process. And, the success of the activation of the PDP context is complicated since a signal of "Activate PDP Context" which sent by the MS (mobile station) be a success if any, received signal of "Activate PDP Context Accept" by the SGSN to the MS, but there must be a success in terms of:

a. GGSN must "know" in advance that there is an MS requesting the activation of the PDP context, which is characterized by "communication" between the SGSN to the GGSN, which form the signal of "Create PDP Context Request" 
b. There should be a success in terms of "Radio Bearer Setup", that means that this process involves a "communication between three elements: MS, RAN and SGSN.

Success condition depends on three things:
a. Transmission of sending and receiving signals,
b. Signal processing in network elements, and
c. The presence of capacity "radio bearer" of the RAN.

\section{Measurement Process}

For every one successful request accessing an internet service from an MS, it will be recorded as follows:

1. At SGSN, there are:

a. Received: signal of "Activate PDP context ", signal of "Create PDP Context Response", and signal of "Update PDP Context Response";

b. Sending: signal of "Create PDP Context Request", signal of "Radio Access Bearer Assignment Request", signal of "Radio Access Bearer Assignment Response", signal of "Update PDP Context Request" and "Activate PDP context Accept".

2. At GGSN, there are:

a. Received: signal of "Create PDP Context Request" and signal of "Update PDP Context Request";

b. Sending: signal of "Create PDP Context Response" and signal of "Update PDP Context Response".

3. At RAN, there are:

a. Received: signal of "Radio Access Bearer Assignment Request" and signal of "Radio Bearer Setup Complete";

b. Sending: signal of "Radio Bearer Setup" and signal of "Radio Access Bearer Assignment Response".

\section{Problem and Analysis}

Problem: assume that, there are 1000 request accessing the internet service from the MS in an area at 1 hour, and the recorded here are the signal records:

1. At SGSN, there are:

a. Received: 1000 signal of "Activate PDP context ", 985 signal of "Create PDP Context Response", and 887 signal of "Update PDP Context Response";

b. Sending: 995 signal of "Create PDP Context Request", 983 signal of "Radio Access Bearer Assignment Request", 900 signal of "Radio Access Bearer Assignment Response", 895 signal of "Update PDP Context Request" and 880 "Activate PDP context Accept".

2. At GGSN, there are: 
a. Received: 991 signal of "Create PDP Context Request" and 981 signal of "Update PDP Context Request";

b. Sending: 988 signal of "Create PDP Context Response" and 890 signal of "Update PDP Context Response".

3. At RAN, there are:

a. Received: 980 signal of "Radio Access Bearer Assignment Request" and 910 signal of "Radio Bearer Setup Complete";

b. Sending: 930 signal of "Radio Bearer Setup" and 904 signal of "Radio Access Bearer Assignment Response".

\section{Analyze the data!}

Analysis:

1. Overall, the performance of the network in serving the request for internet services from the mobile station is $=880 / 1000=88 \%$, and Network Non-Accessibility $=(1000-$ $880) / 1000=12 \%$. This is a relatively large failure. Note: 1000 is the first transmitted signal, that is "Activate PDP context", and 880 is the last signal sent, that is "Activate PDP context Accept"

2. The greatest effect on performance degradation is the failure of RAN to process 980 signal of "Radio Access Bearer Assignment Request", and only sent 930 signal of "Radio Bearer Setup", so in this situation, RAN contribute $5 \%$ of failure.

\section{References}

[1] European Telecommunications Standards Institute. (2011). ETSI Standard TS 102 250-2 v2.2.1: Speech and multimedia Transmission Quality (STQ); QoS aspects for popular services in mobile networks; Part 2: Definition of Quality of Service parameters and their computation.

[2] GSM Association. (2011). GSM Association Standard PRD IR 42: Definition of quality of service parameters and their computation

[3] ITU-T. (1989). ITU-T Recommendation E.800: Definitions of terms related to quality of service.

[4] European Telecommunications Standards Institute. (2011). Speech and multimedia Transmission Quality (STQ), QoS aspects for popular services in mobile networks; Part 1. Assessment of Quality of Service, ETSI TS 102 250-1 V2.2.1 (2011-04).

[5] Hardy, C. William. (2001). QoS Measurement and Evaluation of Telecommunications Quality of Service. John Wiley \& Sons, Ltd. Baffin's Lane, Chichester, West Sussex, PO19 1UD, England.

[6] Sigit Haryadi. (2013). Telecommunication Traffic: Technical and Business Consideration. Lantip Safari Media, Bandung, Indonesia. ISBN: 978-602-18578-5-4.

[7] Sigit Haryadi. (2013). Telecommunication Service and Experience Quality. Lantip Safari Media, Bandung, Indonesia. ISBN: 978-602-18578-6-1.

[8] Haryadi, Sigit; Limampauw, Ivantius. (2012). QoS Measurement of Telephony Services In 3G Networks Using Aggregation Method. Conference Proceeding of TSSA 2012. Denpasar, Indonesia.

[9] Haryadi, Sigit; Nusantara, Sandy. (2012). QoS Measurement of Web Browsing Services In 3G Networks Using Aggregation Method. Conference Proceeding of TSSA 2012. Denpasar, Indonesia.

[10] Haryadi, Sigit; Pramudita, Arnold. (2012). QoS Measurement of Video Streaming Services in a 3G Networks Using Aggregation Method. Conference Proceeding of TSSA 2012. Denpasar, Indonesia. 
[11] Haryadi, Sigit; Andina, Raisha. (2012). QoS Measurement of File Transfer Protocol Services In 3G Networks Using Aggregation Method. Denpasar, Indonesia. 2012.

[12] Haryadi, S. (2018, January 25). Chapter 1. The Concept of Telecommunication Network Performance and Quality of Service. Retrieved from osf.io/mukqb

[13] Haryadi, S. (2018, January 26). Chapter 2 of Network Performance and Quality of Service: Determination of Key Performance Indicator (KPI). Retrieved from osf.io/preprints/inarxiv/6gtnd

[14] Haryadi, S. (2018, January 26). Chapter 3 of Network Performance and Quality of Service: Technical Measurement of a Mobile Network Performance and Quality of Service. Retrieved from osf.io/q4wsz

[15] Haryadi, S. (2018, January 30). Basic Calculation of the Network's Availability and Reliability (Chapter 4 of Network Performance and Quality of Service). Retrieved from osf.io/preprints/inarxiv/z5mwq

[16] Muhammad Rizky Hikmatullah; Sigit Haryadi. (2017). Perceptual evaluation of speech quality over the top call service. 3rd International Conference on Wireless and Telematics (ICWT), Indonesia.

[17] Rizna Nofitasari; Sigit Haryadi. (2017). Self-healing mechanism with RSRP measurement in LTE network. 3rd International Conference on Wireless and Telematics (ICWT), Indonesia.

[18] Fidyatun Nisa; Sigit Haryadi. (2016). Simulation of the fault management with Self-Healing mechanism (case study: LTE Network in Banda Aceh Area). 10th International Conference on Telecommunication Systems Services and Applications (TSSA), Indonesia.

[19] Suci Ramadona; Sigit Haryadi; Dyah Rakhma Aryanti. (2015). Over the top call service key performance indicator. 1st International Conference on Wireless and Telematics (ICWT), Indonesia.

[20] Maya Rahayu; Sigit Haryadi; Dyah Rakhma Aryanti. (2015). Over the Top chat service key performance indicator. 1st International Conference on Wireless and Telematics (ICWT), Indonesia.

[21] Sigit Haryadi. (2016). Telecommunication Quality of Service Concept. Research gate. Available online at

https://www.researchgate.net/publication/313101013_Telecommunication_Quality_of Service_Concept

[22] Sigit Haryadi. (2016). Grade of Service \& Quality of Service Concept and Analysis. Research gate. Available online at https://www.researchgate.net/publication/313101070_Grade_of_Service_Quality_of Service_Concept_and_Analysis

[23]Sigit Haryadi. (2016). Performance Indicator of Telecommunication Service. Research gate. Available online at https://www.researchgate.net/publication/313101244_Performance_Indicator_of_Tele communication_Service. 